Article

\title{
Surface Water Monitoring within Cambodia and the Vietnamese Mekong Delta over a Year, with Sentinel-1 SAR Observations
}

\author{
Binh Pham-Duc ${ }^{1,2, *}$, Catherine Prigent ${ }^{1}$ and Filipe Aires ${ }^{1}$ \\ 1 Laboratoire d'Etudes du Rayonnement et de la Matiére en Astrophysique et Atmosphéres, \\ UMP 8112, l'Observatoire de Paris, 61 Avenue de l'Observatoire, 75014 Paris, France; \\ catherine.prigent@obspm.fr (C.P.); filipe.aires@obspm.fr (F.A.) \\ 2 Space and Aeronautics Department, University of Science and Technology of Hanoi, \\ 18 Hoang Quoc Viet, Cau Giay, 10000 Hanoi, Vietnam \\ * Correspondence: pham.binh@obspm.fr; Tel.: +33-07-8243-5237
}

Academic Editor: Frédéric Frappart

Received: 24 March 2017; Accepted: 19 May 2017; Published: 23 May 2017

\begin{abstract}
This study presents a methodology to detect and monitor surface water with Sentinel-1 Synthetic Aperture Radar (SAR) data within Cambodia and the Vietnamese Mekong Delta. It is based on a neural network classification trained on Landsat- 8 optical data. Sensitivity tests are carried out to optimize the performance of the classification and assess the retrieval accuracy. Predicted SAR surface water maps are compared to reference Landsat- 8 surface water maps, showing a true positive water detection of $\sim 90 \%$ at $30 \mathrm{~m}$ spatial resolution. Predicted SAR surface water maps are also compared to floodability maps derived from high spatial resolution topography data. Results show high consistency between the two independent maps with $98 \%$ of SAR-derived surface water located in areas with a high probability of inundation. Finally, all available Sentinel-1 SAR observations over the Mekong Delta in 2015 are processed and the derived surface water maps are compared to corresponding MODIS/Terra-derived surface water maps at $500 \mathrm{~m}$ spatial resolution. Temporal correlation between these two products is very high ( $99 \%$ ) with very close water surface extents during the dry season when cloud contamination is low. This study highlights the applicability of the Sentinel-1 SAR data for surface water monitoring, especially in a tropical region where cloud cover can be very high during the rainy seasons.
\end{abstract}

Keywords: SAR; Sentinel-1; surface water monitoring; neural network; Mekong Delta; Landsat-8; MODIS

\section{Introduction}

Studying the spatial and temporal distribution of surface water resources is critical, especially in highly populated areas and in regions under climate change pressure. With an increased number of Earth-observation satellites providing a large diversity of remote sensing data, there is now the potential to monitor the surface water at regional to global scale. However, mapping surface water is still challenging. It is difficult to provide products with the accuracy required for a large range of applications (e.g., agriculture, disaster management, and hydrology).

Several methods have already been proposed to detect and monitor surface water with visible and Near-Infrared (NIR) images. Ref. [1] used positive values of the Normalized Difference Water Index (NDWI) to classify water bodies. Ref. [2] applied a threshold on NIR reflectances of the NOAA/AVHRR satellite to delineate lakes. Ref. [3] detected surface water by identifying the positive values of the Modification of Normalized Difference Water Index (MNDWI). Ref. [4] combined NIR data and the Normalized Difference Vegetation Index (NDVI) to detect surface water bodies. However, cloud 
contamination is a stringent constraint for these methods, limiting their application to cloud-free conditions which is very restrictive in some regions (e.g., in the Tropics). Vegetation can also mask the surface water partly or totally. This makes the water detection difficult or impossible under canopy. In addition, the NIR reflectance over highly turbid water can be higher than the red reflectance, introducing confusions in the indices used for the water detection.

Synthetic Aperture Radar (SAR) have become an important source of data to detect flood or monitor surface water as they allow observations regardless of the cloud cover, day and night, with spatial resolution comparable to visible and near-infrared satellite images [5]. SAR instruments have been available on many sensors and platforms (Envisat ASAR, PALSAR, or RADARSAT, for example) providing observations for different areas all over the globe (but normally with a limited number of images available per year in some regions). Flood detection using different SAR observations has been studied by many authors, showcasing the advantages of SAR instruments compared to optical instruments in monitoring floods. Ref. [6] used a single decision tree classifier on two sets of JERS-1 SAR data to classify surface water within the states of North Carolina and South Carolina into five land cover types (water, marsh, flooded forest, field, and non-flooded forest). Although the classifier was simple, they reported an overall classification accuracy of nearly 90\%. Ref. [7] showed the potential of the COSMO-SkyMed data for flood detection by showing case studies in several locations all over the globe (e.g., Tarano River overflow, Italy, April 2009; Pakistan inundation, July-September 2010; Thailand flood, October 2010; and Australia flood, January 2011). COSMO-SkyMed instruments provided very high resolution X-band SAR images, but covered limited areas (the highest spatial resolution is $\sim 1 \mathrm{~m}$ for an observation area of $10 \mathrm{~km} \times 10 \mathrm{~km}$ ). X-band data from TerraSAR-X instrument were also reported suitable for flood mapping under forest canopy in the temperate forest zone in Estonia [8]. Ref. [9] compared four flood detection approaches over five areas (Vietnam, the Netherlands, Mali, Germany, and China) using SAR data from the TanDEM-X mission. Although these four approaches were designed according to different requirements, their performances were satisfactory over the studied areas (17 out of 20 water masks reaching an overall accuracy larger than $90 \%$ ). Other studies using SAR data for water monitoring locally and regionally under different environments can be listed, such as [10-12]. Mapping water bodies at global scale using SAR data was limited due to the lack of global observations, and the fact that SAR data are not easy to access freely. Ref. [13] used multi-year (2005-2012) Envisat ASAR observations to create, for the first time, a global potential water body map at a spatial resolution of $150 \mathrm{~m}$. Errors concentrated along shorelines and coastline, but this global water map has an accuracy of $\sim 80 \%$ compared to the reference data.

The Mekong Delta in Southeast Asia (one of the largest deltas in the world) is a vast triangular plain of approximately $55,000 \mathrm{~km}^{2}$, most of it lower than $5 \mathrm{~m}$ above sea level. The seasonal variation in water level results in rich and extensive wetlands. For instance, the Mekong Delta region covers only $12 \%$ of Vietnam but produces $\sim 50 \%$ of the annual rice (with two or three harvests per year depending on the provinces), represents $\sim 50 \%$ of the fisheries, and $\sim 70 \%$ of the fruit production. In the Delta, the dry season extends from November to April and the rainy season from May to October. Many researches have been carried out to monitor the surface water in the Delta, using both optical and active microwave satellite images. Ref. [14] produced a monthly mean climatology of the water extent from 2000 to 2004 with a spatial resolution of $500 \mathrm{~m}$, using visible and NIR MODIS/Terra data. However, with $85 \%$ to $95 \%$ cloud cover during the wet season over the Mekong Delta [15], remote sensing methods derived from visible and NIR images present some limitations. Different SAR observations have also been exploited to study floods and wetlands over the Delta. Ref. [16] mapped flood occurrence for the year 1996 over the Delta using five ERS-2 observations. Ref. [17] used 60 Envisat ASAR observations during the years 2007-2011 to study the flood regime in the Delta. Thanks to the launch of the Sentinel-1A \&B satellites, as well as the free data policy of the European Space Agency (ESA), Sentinel-1 SAR observations are now regularly and freely accessible for scientific and educational purposes, over large parts of the globe. Similar to previous SAR instruments, Sentinel-1 instruments show strong potential for detecting open water bodies at high spatial resolution [18,19]. 
With the advantage of higher temporal resolution than previous SAR instruments, Sentinel-1 has the ability to monitor the seasonal cycle of water extent every six days over Europe and the boreal region, and with slightly reduced temporal sampling elsewhere. In this study, we propose a methodology using Sentinel-1A SAR observation for monitoring water surface extent within Cambodia and the Mekong Delta for the year 2015. It is based on a Neural Network (NN) algorithm, trained on visible Landsat-8 images (30 m spatial resolution). At the time of this study, the temporal resolution of Sentinel-1 over the Delta was 12 days: it reduced to 6 days after the launch of the Sentinel-1B in April 2016.

The Sentinel-1 SAR data and the ancillary observations are described in Section 2, including the pre-processing steps. Section 3 presents the NN methodology, along with sensitivity tests. Results and comparisons with other products are provided and discussed in Section 4. Section 5 concludes this study.

\section{Sentinel-1 SAR Data and the Ancillary Datasets}

\subsection{Sentinel-1 SAR Data}

Sentinel-1 is a satellite project funded by the European Union and carried out by the European Space Agency. It is a two satellite constellation working at C-band $(5.405 \mathrm{GHz})$. The major objective of the satellites is the observations and monitoring of land and ocean surfaces day and night, under all weather conditions [20]. The satellite operates in four exclusive imaging modes with different spatial resolutions (the highest being $5 \mathrm{~m}$ ) and swaths (up to $400 \mathrm{~km}$ ). The first Sentinel-1A satellite of the pair was launched on 3 April 2014, while the second Sentinel-1B satellite was launched on 22 April 2016. The Sentinel-1 satellites fly along a sun-synchronous, near-polar circular orbit at an altitude of $\sim 693 \mathrm{~km}$. Incidence angle varies between $29^{\circ}$ and $46^{\circ}$. The two satellites provide a re-visiting time of 6 days (it was 12 days before the launch of the Sentinel-1B satellite). Sentinel- 1 satellites have dual polarization capabilities $(\mathrm{HH}, \mathrm{VV}, \mathrm{HH}+\mathrm{HV}$ and $\mathrm{VV}+\mathrm{VH})$, giving final users the ability to access a large variety of applications, including the monitoring of surface water. SAR images from Sentinel-1 satellites are freely downloaded from the sentinel scientific data hub [21].

In this project, $20 \mathrm{~m}$ resolution (10 m pixel spacing) Level-1 Ground Range Detected (GRD) Sentinel-1 images are used, from the Interferometric WideSwath (IW) mode. These images have been detected and projected to ground range using an Earth ellipsoid model provided by ESA. Over the Mekong Delta, there are two polarizations available: the VH and VV polarizations. Some pre-processing steps have to be carried out using the free Sentinel Application Platform (SNAP) software developed by ESA, before moving to the analysis steps (see Figure 1). These pre-processing steps are described in the "SAR Basics with the Sentinel-1 Toolbox in SNAP tutorial" [22].

First, multi-looking processing is applied to each single Sentinel-1 image (both polarizations) to convert to $30 \mathrm{~m}$ spatial resolution (to match with Landsat-8 images). Applying multi-looking at the beginning of the chain reduces the processing time for the next steps since the size of the image is several times smaller than the original one. Second, the image is calibrated to convert values of the raw image from digital number to radar backscatter coefficient $\left(\sigma^{0}\right)$. Third, the Refined Lee filter is applied to reduce the speckle noise and to smooth the radar backscatter coefficient data because this filter maintains details of the standing water boundary [23]. Other filters (Lee, Lee Sigma or Median, for example) were tested, and results showed little differences in terms of water detection. Next, the "terrain correction" tool is used to compensate for distortions in the SAR images, so that the geometric presentation of the image will be as close as possible to the real world. At the end of this step, the image is also re-projected from the satellite projection to the Earth geographic projection, and is ready for applications. To fully cover Cambodia and the Vietnamese Mekong Delta, at least five Sentinel-1 SAR images are needed. Figure 2 (top) provides examples of the SAR backscatter coefficients for VH (a) and VV (b) polarizations, along with the incidence angle (c), over the Tonle Sap Lake, on 17 December 2015. 


Sentinel-1 images
$($ VH \& VV) $\Rightarrow$ Multi-looking $\Rightarrow$ Calibration $\Rightarrow \begin{aligned} & \text { Speckle } \\ & \text { Filter }\end{aligned} \Rightarrow \begin{gathered}\text { Terrain } \\ \text { Correction }\end{gathered} \Rightarrow \begin{aligned} & \text { Sentinel-1 images } \\ & \text { ready for applications }\end{aligned}$

Figure 1. Pre-processing steps for Sentinel-1 Synthetic Aperture Radar (SAR) images.
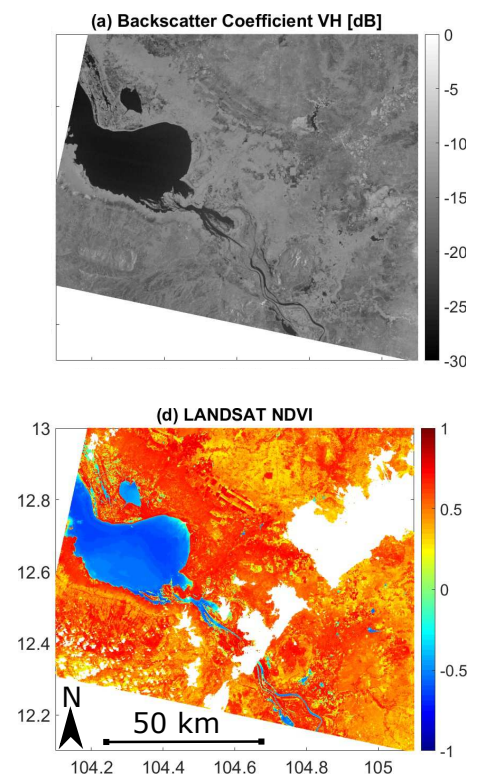

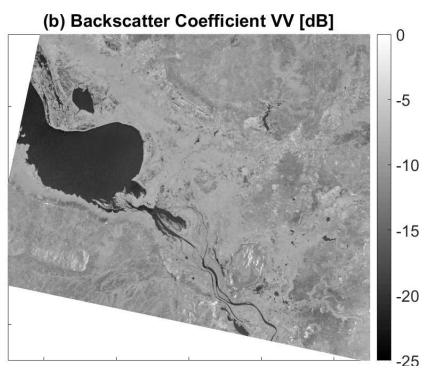

(e) LANDSAT Water Map

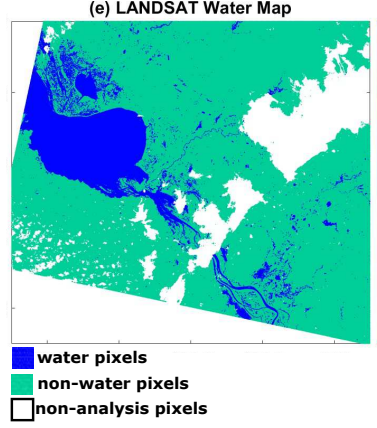

(c) Incidence Angle [degree]
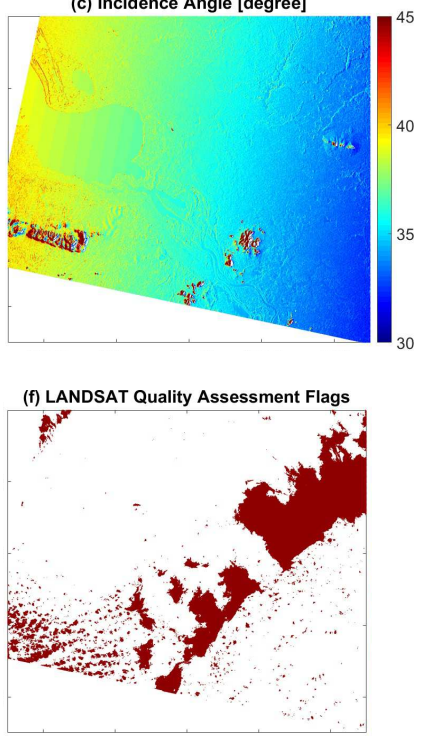

Figure 2. Examples of satellite observations from Sentinel-1 (top) and from Landsat-8 (bottom), over the lower part of the Tonle Sap Lake (Cambodia) after the pre-processing steps: (a) SAR backscatter coefficient at VH polarization; (b) SAR backscatter coefficient at VV polarization; (c) SAR incidence angle; (d) The Normalized Difference Vegetation Index (NDVI) from Landsat-8; (e) Surface water estimated from Landsat-8; and (f) Landsat-8 quality flags. The white areas are cloud-covered pixels detected by the Landsat quality flags, and have been removed. Both Sentinel-1 and Landsat- 8 images were taken on 17 December 2015.

\subsection{Ancillary Datasets}

\subsubsection{Inundation Maps Derived from Landsat-8 Data}

Landsat- 8 satellite collects visible and shortwave images (30 m spatial resolution). NIR wavelength reflects less solar radiation than the red wavelength over water bodies [1,3], and surface water maps can be derived from the NDVI maps (water pixels and non-water pixels correspond to negative and positive values of NDVI, respectively) $[24,25]$. Other indices have been used to detect water, but the NDVI is effective when properly corrected from the atmospheric contamination. In this study, official and reliable atmospheric corrected Landsat-8 NDVI images are ordered directly from the U.S. Geological Survey (USGS) website (https://espa.cr.usgs.gov/index/). To limit cloud effects, only images with less than $10 \%$ of cloud contamination are used. The selected images are further filtered using the Landsat- 8 quality assessment to remove pixels that might be affected by instrument artifacts or subject to cloud contamination. Figure 2 (bottom) shows the NDVI from Landsat- 8 (d), the resulting surface water map based on negative NDVI values (e), and the quality flag (f), for the same regions and the same day (17 December 2015) as previously presented. Over the Lower Mekong Delta (lower than latitude number 15), there are $\sim 250$ Landsat- 8 images available between January 2015 and January 2016 . However, there is only 10\% (27 images) with less than $10 \%$ cloud contamination. Among the remaining images, only $1 / 3$ was selected for this study since they were observed with a time difference of less than 3 days from a Sentinel-1 image. 


\subsubsection{Inundation Maps Derived from MODIS/Terra Data}

In this study, the surface reflectance 8-Day L3 Global $500 \mathrm{~m}$ products from MODIS/Terra (MOD09A1) are used to create surface water maps, mainly based on values of the Enhanced Vegetation Index (EVI), the Land Surface Water Index (LSWI), and the difference between EVI and LSWI by a methodology described in [14]. MODIS surface water maps (500 $\mathrm{m}$ spatial resolution) over the Mekong Delta will be used to compare to the corresponding surface water maps derived from SAR Sentinel-1 observations for 2015. MODIS/Terra data can be downloaded from http:/ / reverb.echo.nasa. gov/reverb/.

All Sentinel-1, Landsat-8 and MODIS/Terra observations used in this study are listed in Tables 1 and 2. Sentinel-1 and Landsat-8 training observations are used to train the NN (Section 3.2). Sentinel-1 and Landsat- 8 test observations are used to test, optimize, and evaluate the performance of the NN (Sections 3.3 and 4.1). NN evaluation is also based on comparisons with MODIS surface water estimates (Section 4.3).

Table 1. List of 9 Sentinel-1 and corresponding Landsat- 8 training (top) and test (bottom) observations used in this study over Cambodia and the Vietnamese Mekong Delta. Maximum gap between Sentinel- 1 and Landsat- 8 observations is only 3 days. The cloud cover percentage is indicated for each Landsat-8 observation.

\begin{tabular}{|c|c|c|c|}
\hline \multicolumn{4}{|c|}{ Sentinel-1 and Landsat-8 Training Observations } \\
\hline Image No & Sentinel-1 & Landsat-8 & Clouds \\
\hline 1 & 16 April 2015 & 14 April 2015 & $6.29 \%$ \\
\hline 2 & 21 April 2015 & 21 April 2015 & $0.05 \%$ \\
\hline 3 & 19 August 2015 & 18 August 2015 & $7.94 \%$ \\
\hline 4 & 17 December 2015 & 17 December 2015 & $4.84 \%$ \\
\hline 5 & 29 March 2016 & 31 March 2016 & $6.22 \%$ \\
\hline 6 & 9 June 2016 & 10 June 2016 & $3.94 \%$ \\
\hline \multicolumn{4}{|c|}{ Sentinel-1 and Landsat-8 Test Observations } \\
\hline Image No & Sentinel-1 & Landsat-8 & Clouds \\
\hline 1 & 5 January 2016 & 2 January 2016 & $0.16 \%$ \\
\hline 2 & 3 February 2016 & 3 February 2016 & $7.5 \%$ \\
\hline 3 & 22 February 2016 & 19 February 2016 & $0.29 \%$ \\
\hline
\end{tabular}

Table 2. List of 20 Sentinel-1 and corresponding MODIS/Terra observations used in this study over Cambodia and the Vietnamese Mekong Delta.

\begin{tabular}{cccc}
\hline \multicolumn{4}{c}{ Sentinel-1 and MODIS/Terra Observations } \\
\hline Image No & Date & Image No & Date \\
\hline 1 & 10 January 2015 & 11 & 14 August 2015 \\
2 & 3 February 2015 & 12 & 26 August 2015 \\
3 & 15 February 2015 & 13 & 7 September 2015 \\
4 & 11 March 2015 & 14 & 19 September 2015 \\
5 & 4 April 2015 & 15 & 1 October 2015 \\
6 & 28 April 2015 & 16 & 13 October 2015 \\
7 & 15 June 2015 & 17 & 25 October 2015 \\
8 & 27 June 2015 & 18 & 6 November 2015 \\
9 & 9 July 2015 & 19 & 30 November 2015 \\
10 & 21 July 2015 & 20 & 24 December 2015 \\
\hline
\end{tabular}




\section{Methodology}

\subsection{Surface Water Information from the Sentinel-1 SAR Images}

Flat water surfaces act like mirrors and reflect almost all incoming energy in the specular direction, thus providing very low backscatter. With this physical principle, detection of surface water is often based, at least partly, on the application of a threshold on the SAR backscatter coefficient, with the low backscatter values attributed to water bodies $[6,7,16,17]$. However, SAR backscatter coefficients over water surfaces are also affected by several mechanisms related to the interaction of the signal with vegetation or with possible surface roughness. The backscattered signals over flooded vegetation in wetlands can be enhanced due to the double-bounce scattering mechanism [26-28]. On the other side, the backscatter coefficients can be affected by vegetation canopy (e.g., rice) above the water surfaces due to volume scattering from the plant components (stems or leaves) [29]. The backscatter coefficients (especially the VV polarization) can also be influenced by the wind-induced surface roughness over open water $[17,30]$. Finally, there might be ambiguities between surface water and other very flat surfaces (such as arid regions), that could provide very similar backscatter signatures [31].

Based on a reference water mask derived from Landsat-8 NDVI, Figure 3 presents the histograms of the backscatter coefficients for $\mathrm{VH}$ and $\mathrm{VV}$ polarizations, separately for water and non-water pixels over the incidence angle range of $30^{\circ}-45^{\circ}$ for the area shown in Figure 2. For both polarizations, the water and non-water histograms are rather well separated, with thresholds of $-22 \mathrm{~dB}$ and $-15 \mathrm{~dB}$ for the VH and VV polarizations, respectively. Using these thresholds, the surface water has been classified separately for each polarization. The classification derived from the VH polarized image had a stronger spatial linear correlation with the reference water mask than the one derived from the VV polarized image ( $72 \%$ compared to $62 \%$ ), confirming a higher sensitivity of the $\mathrm{VH}$ polarization to the presence of surface water [19]. Using both polarizations for the classification increased the correlation $(76 \%)$, confirming that the two polarizations carry different information and that using both of them increases the retrieval accuracy. These findings confirmed the study by [32] where water detection with VV polarization was further refined using multiple-polarization.

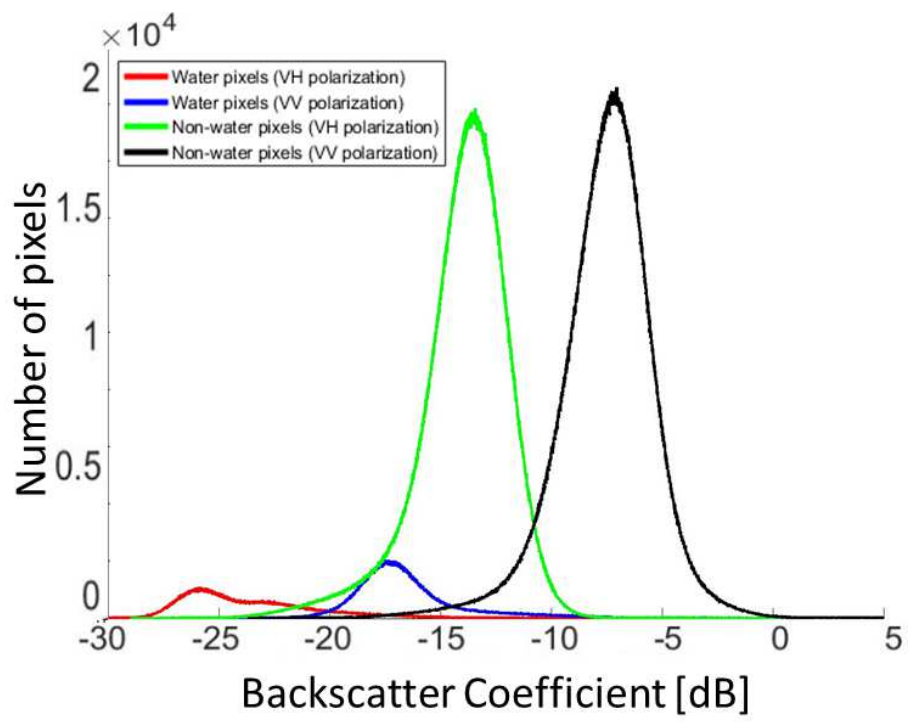

Figure 3. For surface water delineated with Landsat-8, histograms of the water and non-water pixels for the SAR backscatter coefficients in $\mathrm{VH}$ and $\mathrm{VV}$ polarizations for the area shown in Figure 2 (over the incidence angle range of $30^{\circ}$ to $45^{\circ}$ ). 
The effect of the backscatter incidence angle is also tested here. For a collection of pixels located over water (rivers, reservoirs, or lakes), the backscatter coefficient is plotted as a function of the incidence angle between $30^{\circ}$ and $45^{\circ}$ (Figure 4). Similar negative correlations between incidence angle and backscatter coefficients can also be found in [13] with ASAR data over water bodies (from $\sim-5 \mathrm{~dB}$ at $20^{\circ}$ to $\sim-20 \mathrm{~dB}$ at $45^{\circ}$ of incidence angle).

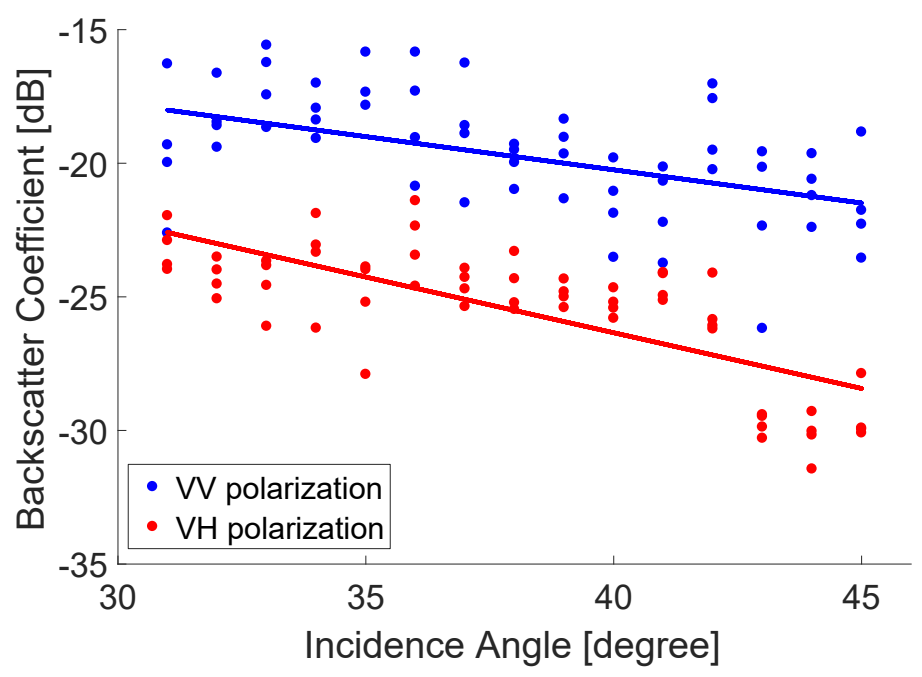

Figure 4. The SAR backscatter coefficients (VH and VV polarizations) from the Sentinel-1 as a function of the incidence angle over water bodies. The linear regression lines are also plotted.

As a conclusion, the SAR backscatter coefficients (VH and VV polarizations) are both sensitive to the presence of water, but with slightly different sensitivities. The effect of the incidence angle, although rather limited within the $29^{\circ}-46^{\circ}$ range of Sentinel-1 SAR, has to be accounted for if a high detection accuracy is required. Simple tests on thresholding techniques illustrated the limitations of these approaches and here we suggest developing a new scheme to delineate the surface water based on Neural Networks.

The temporal dynamics of the backscatter coefficients can also be a source of information and can help disentangle the influence of the other surface parameters [13]. However, this temporal information will not be investigated here.

\subsection{A Neural Network-Based Classification}

Here, we propose training a NN to produce surface water maps from SAR images, over the Mekong Delta. In the remote sensing field, NNs are often used as a regression tool to estimate a quantity. For each pixel, NN input satellite observations are represented by a vector $x$, and the network outputs (i.e., the retrieval) is represented by a vector $y$. However, NNs can also be used as classifiers. In this case, when trained with binary output values ( $y=0$ for non-water, 1 for water surfaces), the $\mathrm{NN}$ becomes a statistical model for the conditional probability $y=P($ surface $=$ water $/ x)$, i.e., the probability of the surface being covered by water knowing the satellite observations $x$. The NN output can then directly be used as an index for water presence probability, but a threshold can also be applied to classify the state as being covered by water or not. The threshold needs to be optimized in order to satisfy some quality criteria, such as overall accuracy or false alarm rates.

The NN classifier needs to be trained in order to perform an optimal discrimination between water and non-water states. A supervised learning is chosen: the $\mathrm{NN}$ will be designed to reproduce an already existing classification. A dataset including a collection of SAR information $x$ and associated surface water state $y$ is first built. Part of it is then used during the training stage in order to determine the optimal parameters of the NN model. The reference dataset in the selected area is provided here by 
a Landsat-8 surface water map (NN outputs), in spatial and temporal coincidence with the Sentinel-1 SAR data (NN inputs). A maximum time difference of 3 days is tolerated, as the two satellites do not fly in phase. Six Landsat- 8 surface water maps are selected, along with the corresponding Sentinel-1 SAR observations (see Table 1 for more details on the training dataset). The selection process for the Landsat-8 images has been described in Section 2.2.1. The images cover parts of the lower Mekong Delta in Vietnam and Cambodia. For each image in the training dataset, the number of non-water pixels is much higher than the number of water pixels. To avoid giving too much weight to the non-water pixels, an equalization of the training dataset is performed: an equal number of non-water and water pixels is selected in the training dataset. For this purpose, non-water pixels are selected randomly in the images, to match the number of water pixels. The total number of training samples is $\sim 10$ million pixels, half water pixels, half non-water pixels. It takes $\sim 5 \mathrm{~h}$ to train the $\mathrm{NN}$ (with the use of a personal computer), but when the training is completed, a surface water map can be produced quickly (after $\sim 3-4 \mathrm{~min}$ ) from any new set of satellite inputs $x$. A test dataset is chosen to measure the performance of the $\mathrm{NN}$ retrieval scheme with data not used in the training process. The NN methodology is summarized in Figure 5.

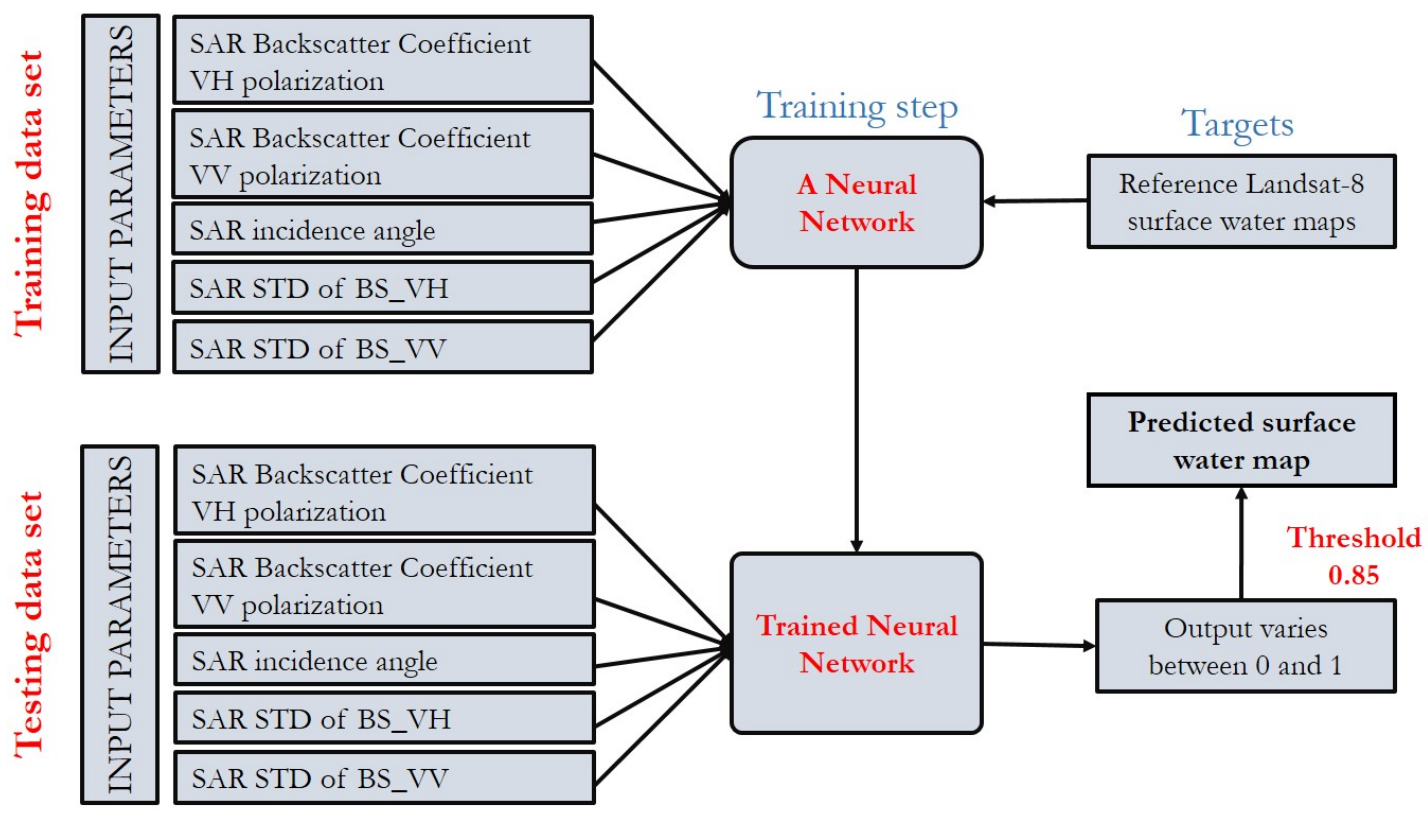

Figure 5. The block diagram of the proposed Neural Network (NN) algorithm.

Several tests were necessary to determine the optimum inputs to the NN, in addition to the obvious ones, i.e., the backscatter coefficients for both polarizations. To limit ambiguities between flat arid surfaces and surface water, and to better capture small rivers, the spatial homogeneity of the backscatter coefficients appeared to be a relevant parameter. The standard deviation of the backscatter coefficients are computed locally over $100 \mathrm{~m} \times 100 \mathrm{~m}$ boxes. As a result, the $\mathrm{NN}$ uses a maximum of five different inputs $x$ :

- $\quad$ SAR backscatter coefficient VH polarization (BS_VH);

- $\quad$ SAR backscatter coefficient VV polarization (BS_VV);

- $\quad$ SAR incidence angle;

- SAR standard deviation of backscatter coefficient VH over $100 \mathrm{~m} \times 100 \mathrm{~m}$ (STD_VH);

- $\quad$ SAR standard deviation of backscatter coefficient VV over $100 \mathrm{~m} \times 100 \mathrm{~m}$ (STD_VV); 
Figure 6 presents an example of the set of five input images and the target surface water map used to train the NN. Missing areas in the maps correspond to Landsat-8 low quality pixels and are excluded from the training. The NN model is asked to find a relationship between these five input parameters and the corresponding water and non-water state.
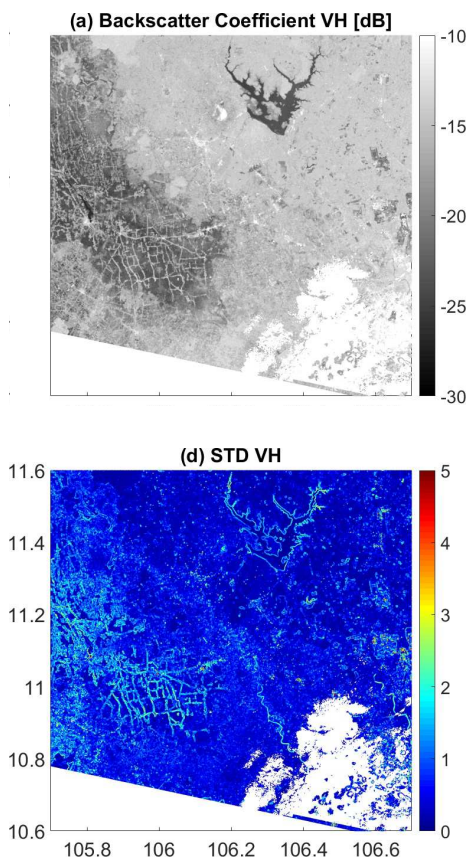
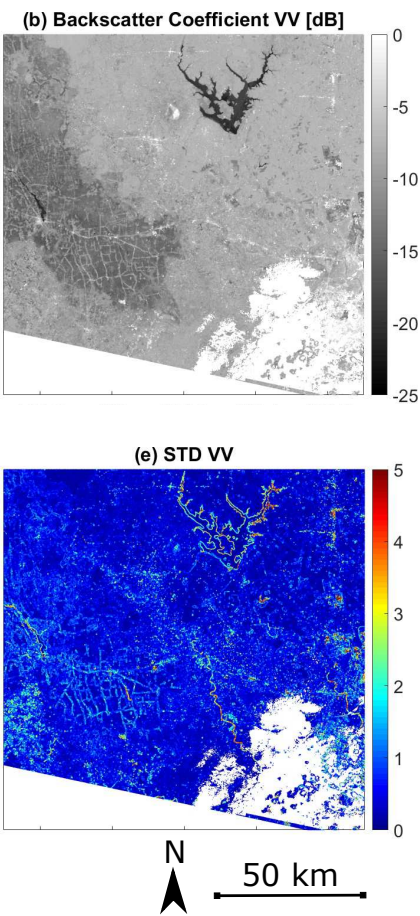

(c) Incidence Angle [degree]

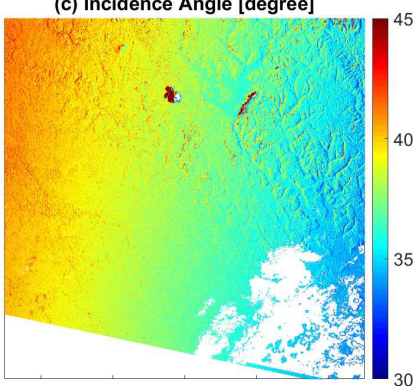

(f) Target Water Map

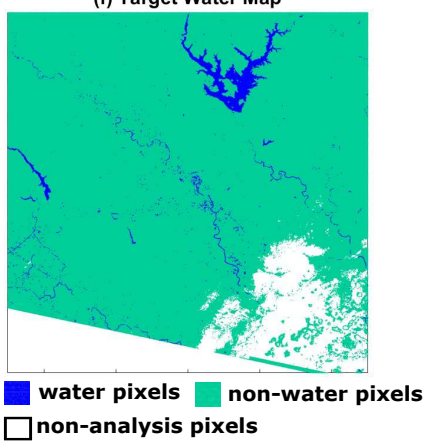

Figure 6. Examples of the five inputs and the target for the NN. (a) SAR backscatter coefficient VH polarization; (b) SAR backscatter coefficient VV polarization; (c) SAR incidence angle; (d) SAR standard deviation of backscatter coefficient VH polarization; (e) SAR standard deviation of backscatter coefficient VV polarization; and (f) Target surface water map based on NDVI from Landsat- 8 . The white areas are cloud-covered pixels detected by the Landsat quality flags, and they have been removed. Sentinel-1 and Landsat-8 images were acquired on 16 and 14 April 2015, respectively.

\subsection{NN Sensitivity Tests}

In this section, we use a test dataset of three SAR Sentinel-1 images and three corresponding Landsat-8 reference surface water maps to make several sensitivity tests in order to optimize the performance of the NN classification (see details of the test data sets in Table 1). Three different sensitivity tests were carried out: (1) selecting the best threshold of the NN output to classify land/water surface; (2) understanding the effect of the equalization of the water and non-water pixels in the NN training dataset; (3) finding the most important satellite NN inputs. The NN performances have been evaluated based on: spatial correlation between the SAR and Landsat-8 surface water maps, overall accuracy of the NN, as well as higher values of true positive (TP) and true negative (TN) percentages. True positive value indicates the NN ability to correctly detect water pixels, while true negative value illustrates its ability to correctly detect non-water pixels (compared to the Landsat- 8 surface water maps).

\subsubsection{Selection of an Optimized Threshold for the NN Output}

The first test is conducted to optimize the output threshold to distinguish water from non-water pixels. Figure 7 shows the histogram of the output of the NN, separating the water and non-water pixels according to the related Landsat- 8 surface water map. The histograms of the water and non-water clusters intersect around 0.9 , meaning that the optimal threshold to separate water from non-water pixels is close to this number. Different thresholds on the NN output values were tested $(0.80,0.85$, and 
0.90): for each one, the confusion matrix and the overall accuracy are calculated, with the corresponding Landsat- 8 images as references. The overall accuracy and the spatial correlation increase from $98 \%$ to $99 \%$ when the threshold increases from 0.80 to 0.90 (Table 3), but the true positive pixel detection decreases from $92 \%$ (with threshold 0.80 ) to $89 \%$ (with threshold 0.90 ) and the false negative pixel detection increases from $8 \%$ to $11 \%$. A threshold of 0.85 is selected here because of its good water detection performance and because it results in the predicted water surface closest to the reference map: $4430 \mathrm{~km}^{2}$ from the Landsat- 8 versus $4420 \mathrm{~km}^{2}$ from the SAR results, i.e., a limited overestimation of $0.4 \%$ as compared to the reference map.

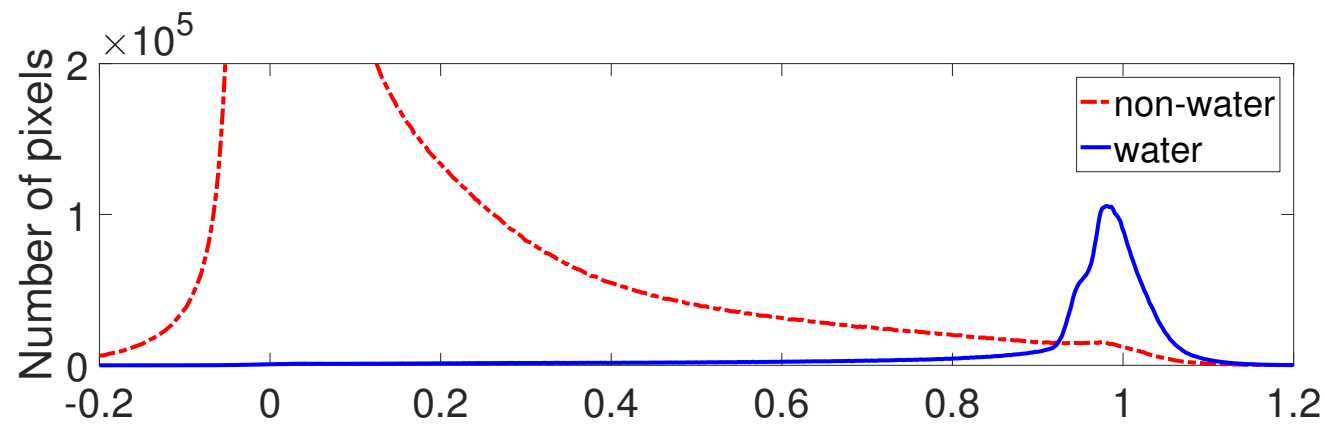

Figure 7. Histograms of the NN outputs, for water (blue) and non-water (dashed red) pixels separately, according to the corresponding Landsat- 8 surface water maps. The NN uses the five initial inputs and the training dataset is equalized. The y axis range is selected to illustrate the peak of the water histogram.

Table 3. Confusion matrix of the NN classification for different thresholds. The NN uses the five initial inputs and the training dataset is equalized.

\begin{tabular}{|c|c|c|c|c|}
\hline \multicolumn{5}{|c|}{ Output Threshold: 0.80} \\
\hline & $\begin{array}{c}\text { Non-Water }(0) \\
\text { (Predicted) }\end{array}$ & $\begin{array}{c}\text { Water(1) } \\
\text { (Predicted) }\end{array}$ & $\begin{array}{c}\text { Overall } \\
\text { Accuracy }\end{array}$ & $\begin{array}{c}\text { Spatial } \\
\text { Correlation }\end{array}$ \\
\hline Non-water(0) (Actual) & $99.3 \%$ & $0.7 \%$ & \multirow{2}{*}{$98 \%$} & \multirow{2}{*}{$91 \%$} \\
\hline Water(1) (Actual) & $8 \%$ & $92 \%$ & & \\
\hline \multicolumn{5}{|c|}{ Output Threshold: 0.85} \\
\hline & $\begin{array}{l}\text { Non-Water(0) } \\
\text { (Predicted) }\end{array}$ & $\begin{array}{c}\text { Water(1) } \\
\text { (Predicted) }\end{array}$ & $\begin{array}{l}\text { Overall } \\
\text { Accuracy }\end{array}$ & $\begin{array}{c}\text { Spatial } \\
\text { Correlation }\end{array}$ \\
\hline Non-water(0) (Actual) & $99.5 \%$ & $0.5 \%$ & \multirow{2}{*}{$99 \%$} & \multirow{2}{*}{$92 \%$} \\
\hline Water(1) (Actual) & $9 \%$ & $91 \%$ & & \\
\hline \multicolumn{5}{|c|}{ Output Threshold: 0.90} \\
\hline & $\begin{array}{l}\text { Non-Water(0) } \\
\text { (Predicted) }\end{array}$ & $\begin{array}{c}\text { Water(1) } \\
\text { (Predicted) }\end{array}$ & $\begin{array}{l}\text { Overall } \\
\text { Accuracy }\end{array}$ & $\begin{array}{c}\text { Spatial } \\
\text { Correlation }\end{array}$ \\
\hline Non-water(0) (Actual) & $99.6 \%$ & $0.4 \%$ & \multirow{2}{*}{$99 \%$} & \multirow{2}{*}{$91 \%$} \\
\hline Water(1) (Actual) & $11 \%$ & $89 \%$ & & \\
\hline
\end{tabular}

\subsubsection{Equalization of Water and Non-Water Pixel Number}

For this test, instead of using an equal number of water and non-water pixels in the training dataset, $10 \%$ of each Sentinel-1 image is selected randomly to train the neural network, meaning that the number of non-water pixels is several times higher (10-15 times depending on each image in the training dataset) than the number of water pixels (as seen in Figure 7). The intersection between histograms of the NN outputs for water pixels (blue) and non-water pixels (red) moves to 0.5 (see the histogram in Figure 8), meaning that the value 0.5 should be selected to separate water from non-water 
clusters. As shown in Table 4, the resulting NN is very efficient at detecting non-water pixels with a true negative detection of $99.7 \%$, but it misses $14 \%$ of the actual water pixels $(86 \%$ of true positive detection only, compared to $91 \%$ with the equalized training dataset-Table 3). The true positive detection of water pixels decreases because in the training database, the non-water pixels are more numerous and as such have more weight in the retrieval than the water pixels. As a consequence, the NN is more effective at detecting non-water pixels, and less effective at detecting water pixels. It is concluded that the use of an equalized training data set is very important in this classification framework.

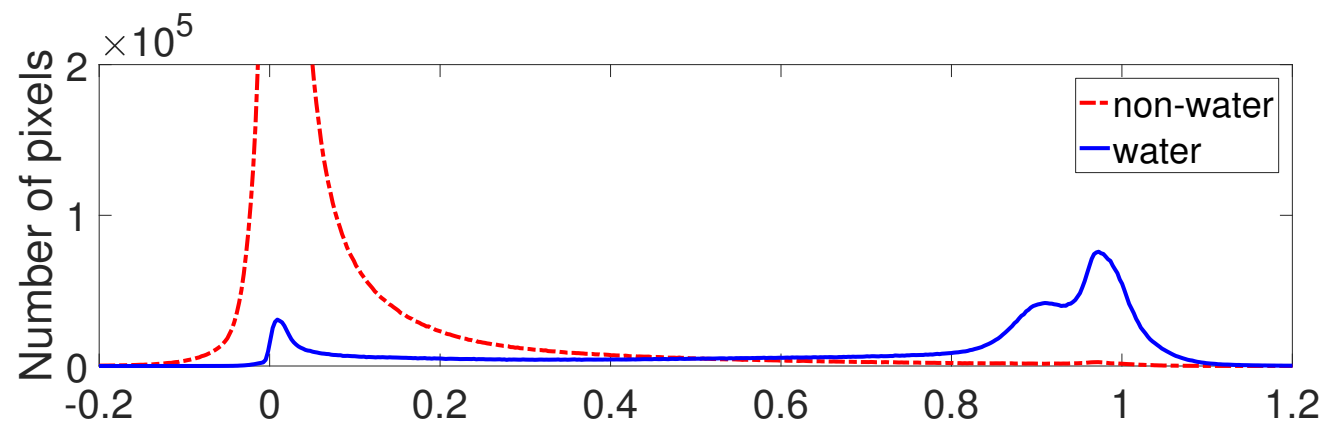

Figure 8. Histograms of the NN outputs, for water (blue) and non-water (dashed red) pixels separately, according to the corresponding Landsat- 8 surface water maps. The NN uses the five initial inputs but the training dataset is not equalized. The y axis range is selected to illustrate the peak of the water histogram.

Table 4. Confusion matrix of the NN without equalization of the training dataset, for an optimum threshold of 0.5 on the NN outputs.

\begin{tabular}{ccc}
\hline & Non-water(0) (Predicted) & Water(1) (Predicted) \\
\hline Non-water(0) (Actual) & $99.7 \%$ & $0.3 \%$ \\
Water(1) (Actual) & $14 \%$ & $86 \%$ \\
\hline
\end{tabular}

\subsubsection{Analyzing the Weight of Each NN Satellite Input}

To identify the most relevant inputs for the NN classification of the water surface, $15 \mathrm{NNs}$ are trained based on all 15 different combinations of five input parameters, and their performances are evaluated following various criteria. Table 5 presents the best results with one to five inputs and illustrates how the overall accuracy of the $\mathrm{NN}$ classification increases when the number of satellite inputs increases, as compared to the reference Landsat- 8 dataset. The NN trained with only the VH backscatter coefficient has a spatial correlation of $78 \%$ and a true positive accuracy (correctly detecting water pixels) of $77 \%$ compared to the reference data. The spatial correlation increases to $79 \%$, and the true positive accuracy rises to $85 \%$ when the standard deviation of the VV backscatter coefficient is added as an input to the NN. The VV backscatter coefficient helps to increase the performance of the NN since both spatial correlation and true positive accuracy increase to $87 \%$ and $90 \%$, respectively. The standard deviation of the VH backscatter coefficient does not significantly improve the accuracy of the NN classification. This is due to the strong linear correlation ( $88 \%$ ) between the spatial standard deviations of the VH and the VV backscatter coefficients (the other linear correlations among the five input parameters of the NN are provided in Table 6). Similar to the standard deviation of the $\mathrm{VH}$ backscatter coefficient, the incidence angle does not have a strong impact on the performance of the NN since its accuracy remains nearly the same after adding the incidence angle as a new input. The input parameters of the $\mathrm{NN}$ classification are listed below, from the most important to the least important one in the $\mathrm{NN}$ processing: 
- $\quad$ Backscatter coefficient VH polarization (BS_VH)

- $\quad$ Standard deviation of backscatter coefficient VV polarization (STD_VV)

- $\quad$ Backscatter coefficient VV polarization (BS_VV)

- Incidence angle

- $\quad$ Standard deviation of backscatter coefficient VH polarization (STD_VH)

Table 5. The NN classification performances when adding input parameters, one at a time.

\begin{tabular}{|c|c|c|c|}
\hline \multicolumn{4}{|c|}{ One Input: BS_VH } \\
\hline & $\begin{array}{l}\text { Non-Water(0) } \\
\text { (Predicted) }\end{array}$ & $\begin{array}{c}\text { Water(1) } \\
\text { (Predicted) }\end{array}$ & $\begin{array}{c}\text { Spatial } \\
\text { Correlation }\end{array}$ \\
\hline $\begin{array}{c}\text { Non-water }(0) \\
\text { (Actual) }\end{array}$ & $98 \%$ & $2 \%$ & \multirow{2}{*}{$78 \%$} \\
\hline $\begin{array}{l}\text { Water(1) } \\
\text { (Actual) }\end{array}$ & $23 \%$ & $77 \%$ & \\
\hline \multicolumn{4}{|c|}{ Two Inputs: BS_VH + STD_VV } \\
\hline & $\begin{array}{l}\text { Non-Water }(0) \\
\text { (Predicted) }\end{array}$ & $\begin{array}{c}\text { Water(1) } \\
\text { (Predicted) }\end{array}$ & $\begin{array}{c}\text { Spatial } \\
\text { Correlation }\end{array}$ \\
\hline $\begin{array}{l}\text { Non-water(0) } \\
\text { (Actual) }\end{array}$ & $98 \%$ & $2 \%$ & \multirow[t]{2}{*}{$79 \%$} \\
\hline $\begin{array}{l}\text { Water(1) } \\
\text { (Actual) }\end{array}$ & $15 \%$ & $85 \%$ & \\
\hline \multicolumn{4}{|c|}{ Three Inputs: BS_VH + STD_VV + BS_VV } \\
\hline & $\begin{array}{l}\text { Non-Water(0) } \\
\text { (Predicted) }\end{array}$ & $\begin{array}{c}\text { Water(1) } \\
\text { (Predicted) }\end{array}$ & $\begin{array}{c}\text { Spatial } \\
\text { Correlation }\end{array}$ \\
\hline $\begin{array}{c}\text { Non-water }(0) \\
\text { (Actual) }\end{array}$ & $99 \%$ & $1 \%$ & \multirow{2}{*}{$87 \%$} \\
\hline $\begin{array}{l}\text { Water(1) } \\
\text { (Actual) }\end{array}$ & $10 \%$ & $90 \%$ & \\
\hline \multicolumn{4}{|c|}{ Four Inputs: BS_VH + STD_VV + BS_VV + Angle } \\
\hline & $\begin{array}{c}\text { Non-Water(0) } \\
\text { (Predicted) }\end{array}$ & $\begin{array}{c}\text { Water(1) } \\
\text { (Predicted) }\end{array}$ & $\begin{array}{c}\text { Spatial } \\
\text { Correlation }\end{array}$ \\
\hline $\begin{array}{c}\text { Non-water }(0) \\
\text { (Actual) }\end{array}$ & $99.5 \%$ & $0.5 \%$ & \multirow{2}{*}{$91 \%$} \\
\hline $\begin{array}{l}\text { Water(1) } \\
\text { (Actual) }\end{array}$ & $10 \%$ & $90 \%$ & \\
\hline \multicolumn{4}{|c|}{ Five Inputs: BS_VH + STD_VV + BS_VV + Angle + STD_VH } \\
\hline & $\begin{array}{l}\text { Non-Water(0) } \\
\text { (Predicted) }\end{array}$ & $\begin{array}{c}\text { Water(1) } \\
\text { (Predicted) }\end{array}$ & $\begin{array}{c}\text { Spatial } \\
\text { Correlation }\end{array}$ \\
\hline $\begin{array}{c}\text { Non-Water }(0) \\
\text { (Actual) }\end{array}$ & $99.5 \%$ & $0.5 \%$ & \multirow{2}{*}{$92 \%$} \\
\hline $\begin{array}{l}\text { Water(1) } \\
\text { (Actual) }\end{array}$ & $9 \%$ & $91 \%$ & \\
\hline
\end{tabular}


Table 6. Linear correlations among the five potential NN inputs.

\begin{tabular}{cccccc}
\hline & BS_VH & BS_VV & STD_VH & STD_VV & ANGLE \\
\hline BS_VH & $100 \%$ & & & & \\
BS_VV & $84 \%$ & $100 \%$ & & & \\
STD_VH & $24 \%$ & $20 \%$ & $100 \%$ & & \\
STD_VV & $21 \%$ & $21 \%$ & $88 \%$ & $100 \%$ & \\
ANGLE & $25 \%$ & $22 \%$ & $11 \%$ & $6 \%$ & $100 \%$ \\
\hline
\end{tabular}

To conclude, the water detection ability of the proposed NN increased when the input parameters are carefully selected and when an optimal output threshold is selected. An equal number of water and non-water pixels should be used in the training dataset to ensure that the NN performs equally well in classifying water and non-water clusters. The STD_VH provides limited additional information to the NN due to its strong linear correlations with the other NN inputs. The incidence angle also plays a limited role in the NN performance. This is partly due to the rather narrow range of incidence angle, from $29^{\circ}$ to $46^{\circ}$.

\section{Results and Comparisons with Other Surface Water Products}

The following results and comparisons involve the optimized version of the NN classification with five input parameters (an equalization of water and non-water pixels, and the output threshold is 0.85). In Section 4.1, the SAR-predicted surface water maps are calculated for two test areas in the Mekong Delta, and compared to Landsat-8 surface water maps over the Tonle Sap Lake in Cambodia and over the Mekong river in Vietnam (see test dataset in Table 1). Other regions were tested but the results are not shown here. Due to the lack of in-situ local inundation maps at the time of this study, we do not have a reference dataset to confirm the accuracy of the Landsat- 8 based maps. Therefore, an inter-comparison between Sentinel-1 estimate and other existing estimates is the only way to evaluate the new wetland product based on SAR Sentinel-1 data. First, the results are evaluated with respect to the floodability map derived mainly from the HydroSHEDS topography dataset [33], developed by [34] (Section 4.2). Second, time series of the SAR-derived surface water over the Mekong Delta is compared to the MODIS/Terra-derived inundation maps based on the methodology described by [14], for 2015 (Section 4.3)

\subsection{Evaluation of the SAR NN Classification Method}

Figure 9 shows the results of the classification applied over the Tonle Sap Lake in Cambodia (top) and over the Mekong river in Vietnam (bottom), in February 2016. Figure 9a,d show the SAR-predicted surface water maps, Figure $9 \mathrm{~b}$,e present the reference Landsat- 8 surface water maps, whereas the differences between these two surface water maps are shown in Figure 9c,f.

Over the Tonle Sape Lake, both Sentinel and Landsat images were acquired on the same day (3 February 2016). The spatial correlation between the two surface water maps is $94 \%$. The confusion matrix for this area is given in Table 7 (left). Overall accuracy of the classification is $99 \%$, with a true positive water detection of $93.5 \%$, and a false negative percentage of $6.5 \%$. The classification correctly detects more than $99.6 \%$ of non-water pixels compared to the reference map. The classification slightly underestimates the surface water coverage by $\sim 2.5 \%$. This is $961 \mathrm{~km}^{2}$ compared to the reference surface water map derived from the Landsat-8 images of $986 \mathrm{~km}^{2}$.

The second case study is carried out over the Mekong river and its surrounding areas (latitude range $\left[10.8^{\circ} \mathrm{N}-11.8^{\circ} \mathrm{N}\right]$ and longitude range $\left.\left[104.6^{\circ} \mathrm{E}-105.6^{\circ} \mathrm{E}\right]\right)$. The optical Landsat- 8 images were taken on 19 February 2016 and the SAR Sentinel-1 images were taken 3 days later, on 22 February 2016. These Sentinel and Landsat images were not acquired on the same day, but within 3 days in the middle of the dry season when land surfaces in this area are not expected to change much. Similar to the first case study, the classification works well, even though the environment here is rather complex, with rivers and vegetated wetlands. The overall accuracy is $98.8 \%$, with a spatial correlation of nearly $82 \%$ 
with the Landsat- 8 reference surface water map. Confusion matrix for this area is shown in Table 7 (right) where the true positive percentage is $85.7 \%$, the false negative percentage $14.3 \%$, and $99.2 \%$ of non-water pixels are classified correctly. The total surface water area derived from Landsat data is $325 \mathrm{~km}^{2}$, and it is $355 \mathrm{~km}^{2}$ predicted from the NN.
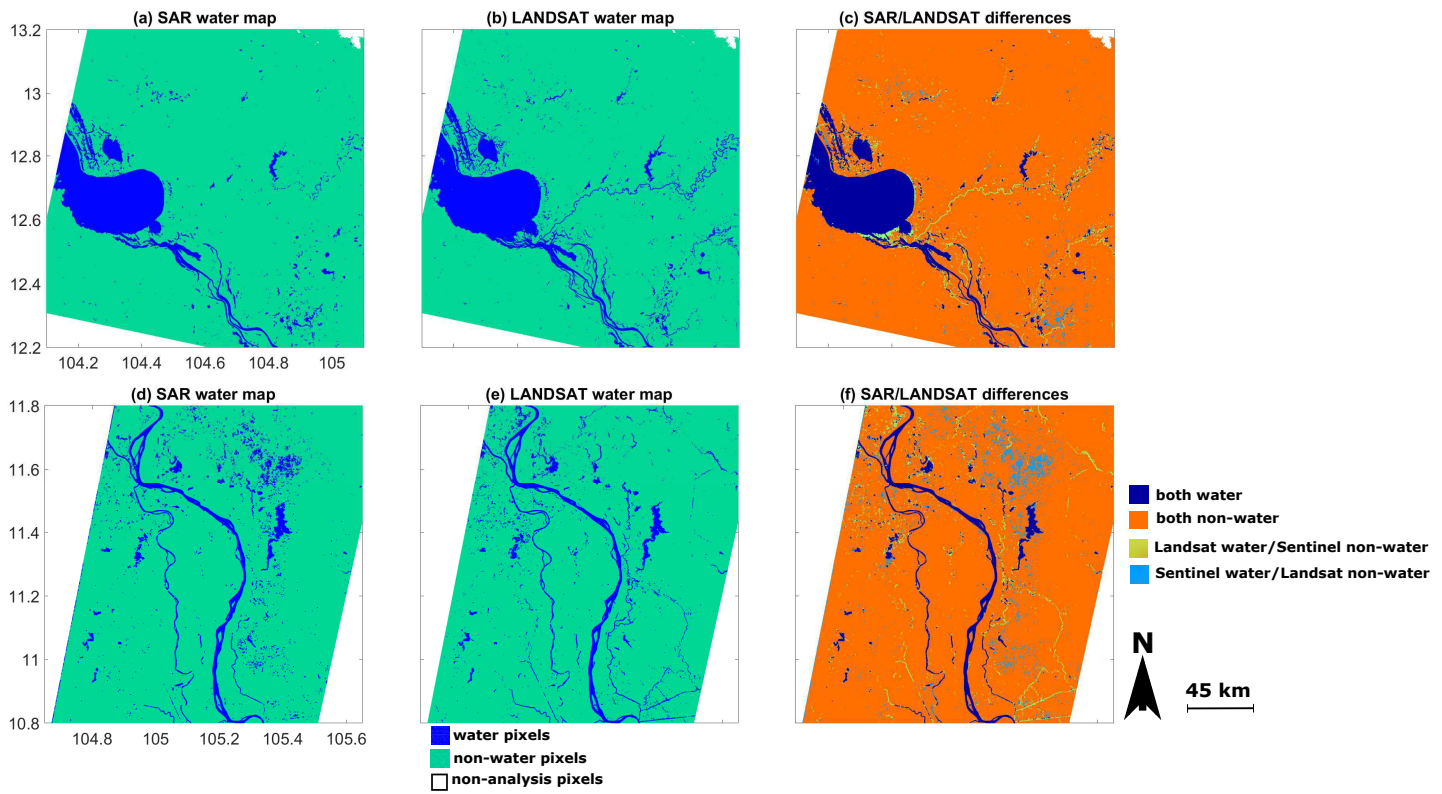

Figure 9. (a,d) SAR surface water maps; (b,e) Landsat-8 surface water maps; and (c,f) their differences; over the Tonle Sap Lake (left), and over the Mekong river (right), for February 2016. Blue color presents water pixels while orange color presents non-water pixels detected by both Sentinel and Landsat, green color is Landsat water/Sentinel non-water pixels, and light blue color is Sentinel water/Landsat non-water pixels.

Table 7. Confusion matrices (in numeric and percentage forms) of the SAR-predicted surface water maps and the Landsat-8 reference surface water maps, over the Tonle Sap Lake (Left) and over the Mekong River (Right).

\begin{tabular}{cccccc}
\hline & Tonle Sap Lake & & \multicolumn{3}{c}{ Mekong River } \\
\hline & $\begin{array}{c}\text { Non-water(0) } \\
\text { (Predicted) }\end{array}$ & $\begin{array}{c}\text { Water(1) } \\
\text { (Predicted) }\end{array}$ & & $\begin{array}{c}\text { Non-water(0) } \\
\text { (Predicted) }\end{array}$ & $\begin{array}{c}\text { Water(1) } \\
\text { (Predicted) }\end{array}$ \\
\hline $\begin{array}{c}\text { Non-water(0) } \\
\text { (Actual) }\end{array}$ & $\begin{array}{c}11,641,078 \\
(99.6 \%)\end{array}$ & $\begin{array}{c}44,493 \\
(0.4 \%)\end{array}$ & $\begin{array}{c}\text { Non-water(0) } \\
\text { (Actual) }\end{array}$ & $\begin{array}{c}10,983,583 \\
(99.2 \%)\end{array}$ & 85,096 \\
\hline Water(1) & 71,884 & $1,023,457$ & Water(1) & 51,611 & 309,982 \\
(Actual) & $(6.5 \%)$ & $(93.5 \%)$ & (Actual) & $(14.3 \%)$ & $(85.7 \%)$ \\
\hline
\end{tabular}

The same results are found when applying the NN classification to other areas. To conclude this comparison, the proposed NN methodology correctly detected $\sim 90 \%$ of the water pixels observed by Landsat- 8 , with a spatial correlation of $\sim 90 \%$. The NN works better over open water bodies than over other heterogeneous environments. For instance, the NN has difficulties detecting small river branches (Southeast of the Tonle Sap Lake in Figure 9-top panel) although they are clearly detected with Landsat-8 images. The NN can provide water maps with high accuracy compared to the reference Landsat- 8 water maps; there are differences between them. Errors could come from the following factors: 
- The SAR responses can be affected by complex interactions with the terrain and the vegetation, especially along small river banks. It can be difficult to account for this local complexity in the methodology.

- In the SAR water detection method, as in any other classifications method scheme, different parameters were selected to optimize the overall performance of the method, but local ambiguities can still exist.

- $\quad$ Sentinel-1 and Landsat-8 data are not always acquired on the same day.

- Using Landsat-8 quality flags, we can remove cloud-covered pixels, but we cannot detect cloud-shadow pixels causing ambiguities in the NN training dataset.

- Reference surface water maps derived from negative NDVI values on the Landsat-8 images are not always perfect. Water under vegetation can be difficult to detect with Landsat- 8 observations. The NDVI values can also be impacted for highly turbid waters where the NIR reflectance can be higher than the red reflectance.

\subsection{Evaluation Using a Topography-Based Floodability Index}

A global floodability index based on topography has been developed by [34]. It uses mainly the Hydrological data and maps based on SHuttle Elevation Derivatives at multiple Scales (HydroSHEDS) dataset [33] that has been derived from elevation measured by the Shuttle Radar Topography Mission (SRTM) satellite. This floodability index provides a static map of an estimate of the probability for a pixel to be inundated (between $0 \%$ and 100\%) at the spatial resolution of $90 \mathrm{~m}$, based only on topography information (such as slope in the pixel, distance to the closest river, difference of elevation with the closest river). Figure 10a presents this floodability index map over the whole Mekong Delta. As expected, all rivers and lakes in this area have a very high probability of being inundated (over $80 \%$ ). Since this index is based only on topography, its reliability is higher for natural environments and it can be less precise over regions with strong anthropic impact such as irrigated areas. The floodability data is upscaled from $90 \mathrm{~m}$ to $30 \mathrm{~m}$ spatial resolution to compare with predicted SAR surface water maps over the Tonle Sap Lake and the Vietnamese Mekong Delta. Each floodability pixel is divided into a $3 \times 3$ matrix with the same value, and projected onto the Sentinel- 1 grid. By comparing these two products, we can see where and how Sentinel- 1 water pixels are located with respect to the floodability index, and test the consistency between two independent products. Figure 10b-e show floodability maps at $30 \mathrm{~m}$ spatial resolution and predicted Sentinel- 1 water maps, over four different areas in the Mekong Delta. SAR surface water areas are generally located in areas with high predicted inundation probabilities, as expected (see Table 8). A total of $98 \%$ of the SAR surface water pixels are located in areas where the floodability index is greater than $60 \%$, while only $2 \%$ of the SAR surface water pixels are located in areas with a lower floodability index $(\leq 60 \%)$. As mentioned earlier, the floodability index only relies upon topography information, and it can be less precise over regions with strong anthropic activities, such as irrigation. There are many rice paddies in the Lower Mekong Delta, and these irrigated fields can be missed by the floodability index, contributing to the $15 \%$ errors of SAR water pixels located in areas with a floodability index less than $80 \%$. In the future, in complex-topography environments where SAR only data could not provide the required accuracy for the water classification (the Red River Delta in the North of Vietnam, for example), the floodability index information could be added as another input to the NN to improve the classification performance.

Table 8. Performance of the SAR surface water classification for different ranges of floodability index.

\begin{tabular}{ccccc}
\hline Floodability Index & $\leq \mathbf{4 0}$ & $\mathbf{4 0 - 6 0}$ & $\mathbf{6 0 - 8 0}$ & $\geq \mathbf{8 0}$ \\
\hline $\begin{array}{c}\text { Percentage of surface water pixels } \\
\text { detected by the NN classification }\end{array}$ & $1 \%$ & $1 \%$ & $13 \%$ & $85 \%$ \\
\hline
\end{tabular}


(a)

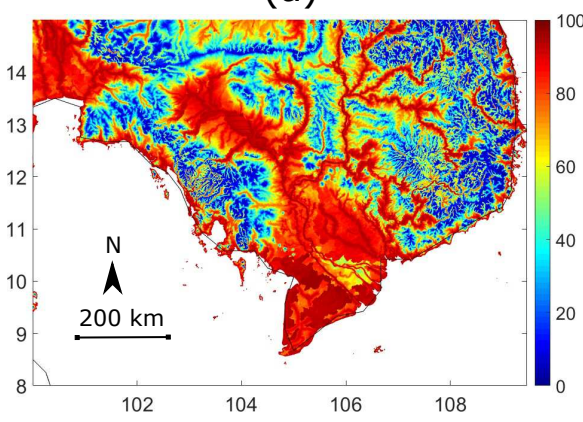

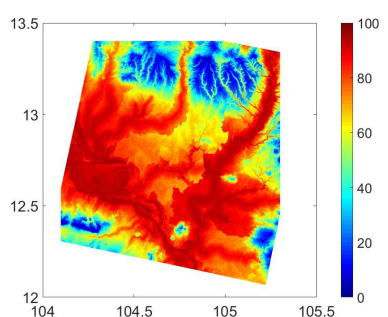
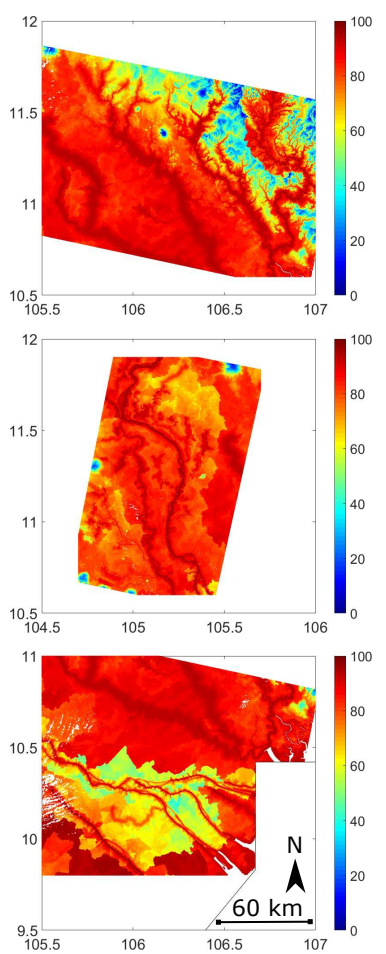

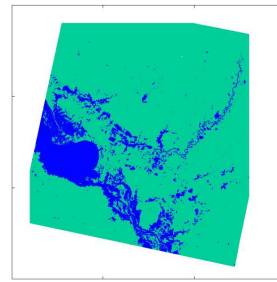

(b)
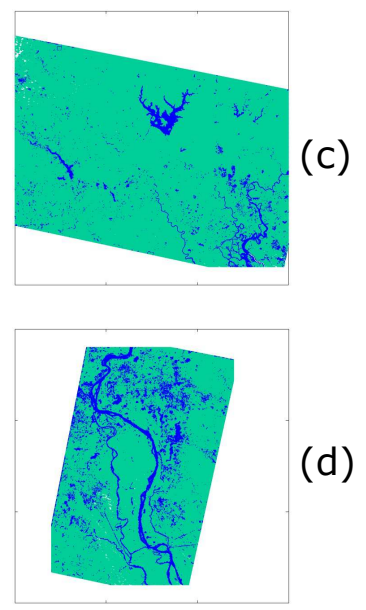

(d)

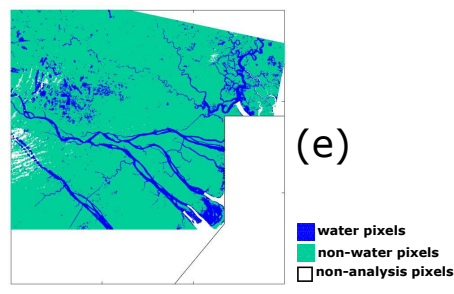

Figure 10. (a) Topography-based floodability index map over the Mekong Delta from [34]. (b-e) Comparisons of floodability index maps and SAR-predicted surface water maps for four areas over Cambodia and the Vietnamese Mekong Delta.

\subsection{Comparisons with MODIS/Terra-Derived Inundation Maps}

In this section, the $30 \mathrm{~m}$ SAR surface water maps are compared to the $500 \mathrm{~m}$ MODIS/Terra-derived inundation maps, for a region in the Mekong Delta. One year (2015) of SAR Sentinel-1 and MODIS/Terra data are extracted, over the same region (latitude $\left[9.8^{\circ} \mathrm{N}-11.3^{\circ} \mathrm{N}\right]$; longitude $\left[104.75^{\circ} \mathrm{E}-107^{\circ} \mathrm{E}\right]$ ). The MODIS inundation maps are derived from the method described by [14]. We re-produced their methodology to calculate inundation maps with three different states of non-water, water, and mixed pixels, respectively. The total MODIS surface water is the sum of the water pixels $(100 \%$ area is inundated) and mixed pixels (part of these pixels is inundated). For a mixed pixel, we tested two hypothesis: $25 \%$ or $50 \%$ of the pixel is inundated.

Twenty Sentinel-1 SAR observations are available over the selected region for the year 2015 (less than two images per month-see Table 2). The surface water extent calculated from the SAR and MODIS data are presented in Figure 11. With the first assumption (25\% of a mixed MODIS pixel is covered by water), the two surface water extents have very similar seasonal cycles and amplitudes, with a correlation of $\sim 99 \%$ (Figure 11-bottom). For the second assumption (the surface water extent of a mixed pixel is increased to 50\%), the difference in surface water areas increases (without significant changes in the seasonal cycle with still high correlation with the SAR surface water time series). With both hypotheses, the SAR and MODIS surface water extents reach their maximum at the same time (around 20 October 2015). Total inundated areas derived from SAR and MODIS are very close 
during the dry season (January to July). The cloud contamination of the MODIS estimate is low during that season. During the rainy season, more cloud contamination is expected in the MODIS estimates, and the discrepancies between the two surface water extents increase. The SAR-derived surface water estimate is expected to be more reliable due to its insensitivity to the cloud cover, but at this stage there is no convincing dataset at this spatial resolution to confirm it, as mentioned before.

To evaluate the consistency of the spatial structure between the SAR-derived and the MODIS-derived surface water maps, 10 SAR Sentinel-1 images were downloaded to cover the whole Mekong Delta and the Tonle Sap Lake (five images in May and five images in October 2015). For comparison purposes and to calculate the spatial correlation, the SAR surface water maps are aggregated from the $30 \mathrm{~m}$ resolution to the $500 \mathrm{~m}$ resolution of the MODIS-derived inundation maps (see Figure 12a,c). As a consequence, Sentinel-1-derived inundation maps are not binary (0 for non-water pixels or 1 for water pixels), but they are converted into a percentage of surface water at $500 \mathrm{~m}$ spatial resolution. For the dry season (Figure 12a,b-May 2015), the spatial correlation between the two surface water maps is $68 \%$. A total of $4 \%$ of the area is inundated for the SAR estimation, while it is $5 \%$ for the MODIS estimates. For the rainy season (October 2015), the spatial correlation of the two maps increases to $78 \%$, with $8 \%$ inundated area with the SAR and $11 \%$ with MODIS. For these calculations, we used the hypothesis of $25 \%$ inundation of the MODIS mixed pixels. Although SAR-derived and MODIS-derived water maps have a very similar seasonal cycle and similar spatial distribution of the water bodies, confirming the wetland seasonal cycle over this region, there are differences in the total surface of inundated areas. It comes mainly from the difference of spatial resolution between the two satellites. First, MODIS sensors cannot detect very small surface water fractions due to their spatial resolution. Second, the MODIS mixed pixels include water surfaces, vegetation surface and bare soil, and the percentage of each surface type within the pixel is not quantified.

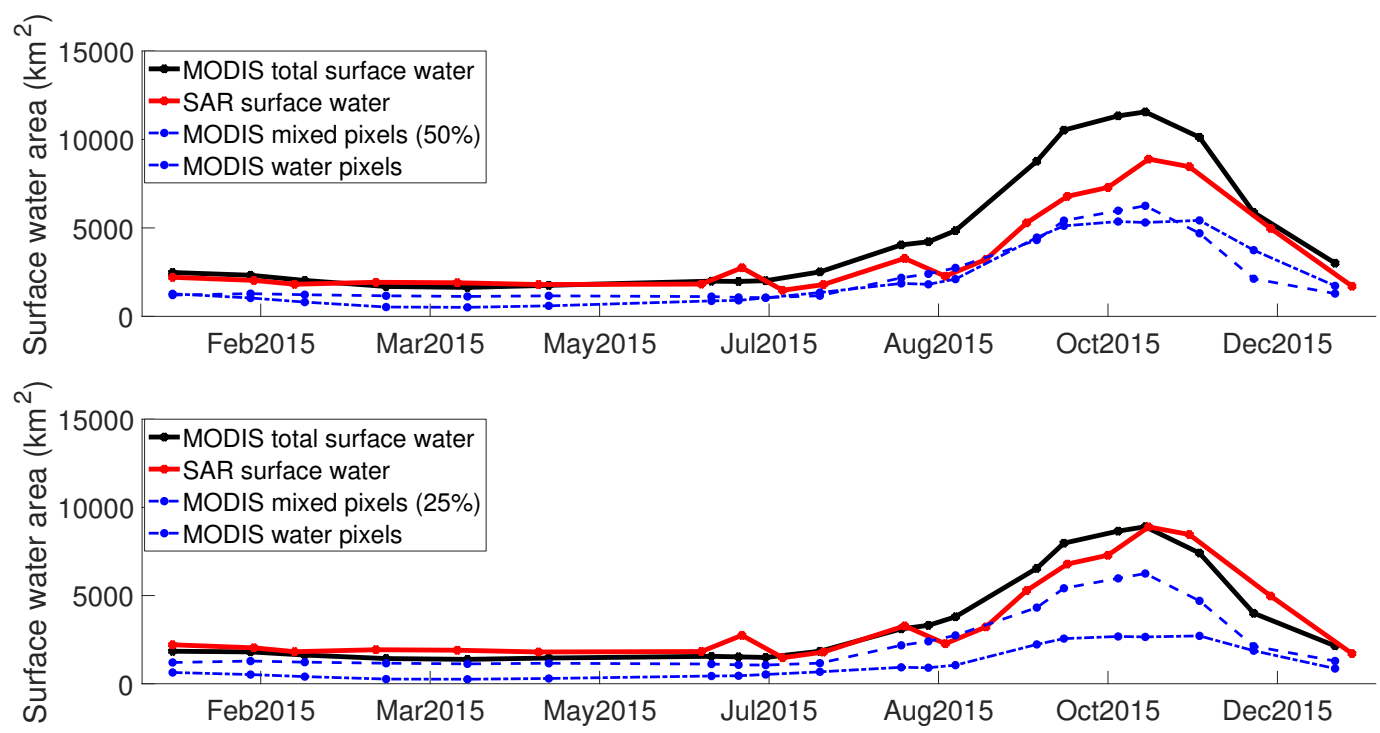

Figure 11. Time series of the surface water detected by SAR (red) and MODIS data (black), over the Mekong Delta (Latitude $\left[9.8^{\circ} \mathrm{N}-11.3^{\circ} \mathrm{N}\right]$; Longitude $\left[104.75^{\circ} \mathrm{E}-107^{\circ} \mathrm{E}\right]$ ), for 2015 . Two hypotheses are tested for the MODIS mixed pixels: 50\% inundated (top Panel), and 25\% inundated (bottom Panel). 

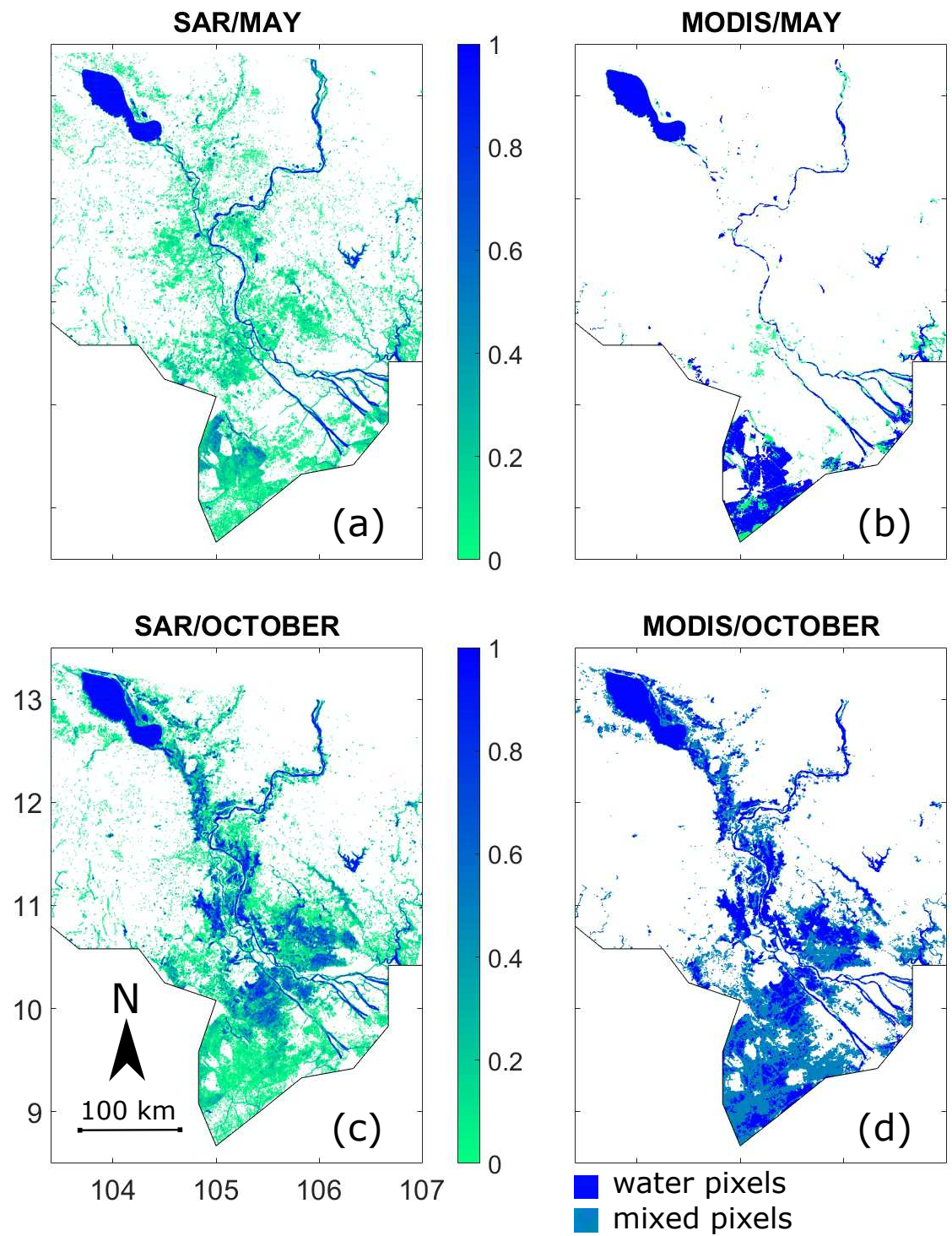

Figure 12. (a,c) SAR and (b,d) MODIS surface water maps at $500 \mathrm{~m}$ resolution over the Mekong Delta in May $(\mathbf{a}, \mathbf{b})$ and October $(\mathbf{c}, \mathbf{d}) 2015$.

\section{Conclusions and Perspectives}

This study presents a methodology to monitor and quantify surface water under all weather conditions within Cambodia and the Mekong Delta in Vietnam, using high quality Sentinel-1 SAR observations, freely available online. The methodology is based on a neural network classification trained with optical Landsat-8 images at $30 \mathrm{~m}$ spatial resolution. The information content of each satellite input is analyzed and the inputs are selected to optimize the performance of the classification. This method allows the detection of surface water with good accuracy when compared to visible and NIR data under clear sky conditions, as well as when compared to a floodability map derived from topography data. Surface water maps derived from the proposed NN show a spatial correlation of $\sim 90 \%$ when compared to Landsat- 8 water maps, with a true positive water detection of $\sim 90 \%$. Compared to MODIS/Terra water maps over the Delta in 2015, our products share the same wetland seasonal cycle and dynamics, with a temporal correlation of $\sim 99 \%$.

In the future, we will first apply the method to other areas under similar environments in southeast Asia and in other parts of the globe, and second we will test it in more vegetated environments. The final goal is to develop a general method capable of performing at the global scale to exploit the 
full spatial coverage of the Sentinel-1 mission. For this purpose, several approaches will be tested to improve the retrieval scheme. First, the introduction of a priori information from a topography-based floodability index will increase information on flooding and reduce ambiguities in the SAR signal with other surface parameters. Second, with the launch of the optical Sentinel-2 satellite, Sentinel-2 observations could be used to replace Landsat- 8 data, and to train the SAR surface water classification under clear sky conditions. The classification could then be extended to the cloudy areas using the SAR data. Third, the temporal information in the SAR backscatter could also be exploited (i.e., minimum or standard deviation of the time series) as this information has been shown to improve the detection of floods [13]. Finally, the high-resolution inundation extent retrieval maps could be post-processed in order to reduce the inherent noise in such high-spatial retrievals. We plan to test random walk techniques for that purpose.

Acknowledgments: We would like to thank Toshihiro Sakamoto for proving the methodology to derive the MODIS $500 \mathrm{~m}$ surface water maps. We are thankful to Simon Munier for interesting discussions and for sharing some of his tools in the framework of his ESA-funded postdoc (CCI Living Planet Fellowship AO/1-7829/14/I-MB). We also thank Thuy Le Toan, Stéphane Jacquemoud, Thanh Ngo Duc, and Nicolas Delbart for interesting discussions and suggestions for this work. This study was financially supported by a PhD fellowship from the Vietnam International Education Development (911 project). We would like to thank three anonymous reviewers for their helpful comments and suggestions that helped to improve the quality of this manuscript.

Author Contributions: Catherine Prigent, Filipe Aires and Binh Pham-Duc conceived and designed the experiments; Binh Pham-Duc performed the experiments; Catherine Prigent, Binh Pham-Duc and Filipe Aires analyzed the data; Filipe Aires, Catherine Prigent and Binh Pham-Duc contributed reagents/materials/analysis tools; Binh Pham-Duc, Catherine Prigent and Filipe Aires wrote the paper. All authors contributed to the discussion of results and the preparation of the manuscript.

Conflicts of Interest: The authors declare no conflict of interest.

\section{References}

1. McFeeters, S.K. The use of the Normalized Difference Water Index (NDWI) in the delineation of open water features. Int. J. Remote Sens. 1996, 17, 1425-1432.

2. Bryant, R.G.; Rainey, M.P. Investigation of flood inundation on playas within the Zone of Chotts, using a time-series of AVHRR. Remote Sens. Environ. 2002, 82, 360-375.

3. $\mathrm{Xu}, \mathrm{H}$. Modification of normalised difference water index (NDWI) to enhance open water features in remotely sensed imagery. Int. J. Remote Sens. 2006, 27, 3025-3033.

4. Cretaux, J.F.; Berge-Nguyen, M.; Leblanc, M.; Abarca Del Rio, R.; Delclaux, F.; Mognard, N.; Lion, C.; Pandey, R.K.; Tweed, S.; Calmant, S.; et al. Flood mapping inferred from remote sensing data. Int. Water Technol. J. 2011, 1, 48-62.

5. Brisco, B.; Touzi, R.; Sanden, J.J.V.D.; Charbonneau, F.; Pultz, T.J.; D'Iorio, M. Water resource applications with RADARSAT-2: A preview. Int. J. Digit. Earth 2008, 1, 130-147.

6. Wang, Y. Seasonal change in the extent of inundation on floodplains detected by JERS-1 Synthetic Aperture Radar data. Int. J. Remote Sens. 2004, 25, 2497-2508.

7. Pierdicca, N.; Pulvirenti, L.; Chini, M.; Guerriero, L.; Candela, L. Observing floods from space: Experience gained from COSMO-SkyMed observations. Acta Astronaut. 2013, 84, 122-133.

8. Voormansik, K.; Praks, J.; Antropov, O.; Jagomagi, J.; Zalite, K. Flood Mapping With TerraSAR-X in Forested Regions in Estonia. IEEE J. Sel. Top. Appl. Earth Obs. Remote Sens. 2014, 7, 562-577.

9. Martinis, S.; Kuenzer, C.; Wendleder, A.; Huth, J.; Twele, A.; Roth, A.; Dech, S. Comparing four operational SAR-based water and flood detection approaches. Int. J. Remote Sens. 2015, 36, 3519-3543.

10. Bartsch, A.; Pathe, C.; Wagner, W.; Scipal, K. Detection of permanent open water surfaces in central Siberia with ENVISAT ASAR wide swath data with special emphasis on the estimation of methane fluxes from tundra wetlands. Hydrol. Res. 2008, 39, 89-100.

11. Brisco, B.; Short, N.; van der Sanden, J.; Landry, R.; Raymond, D. A semi-automated tool for surface water mapping with RADARSAT-1. Can. J. Remote Sens. 2009, 35, 336-344.

12. Reschke, J.; Bartsch, A.; Schlaffer, S.; Schepaschenko, D. Capability of C-Band SAR for Operational Wetland Monitoring at High Latitudes. Remote Sens. 2012, 4, 2923-2943. 
13. Santoro, M.; Wegmuller, U.; Lamarche, C.; Bontemps, S.; Defourny, P.; Arino, O. Strengths and weaknesses of multi-year Envisat ASAR backscatter measurements to map permanent open water bodies at global scale. Remote Sens. Environ. 2015, 171, 185-201.

14. Sakamoto, T.; Van Nguyen, N.; Kotera, A.; Ohno, H.; Ishitsuka, N.; Yokozawa, M. Detecting temporal changes in the extent of annual flooding within the Cambodia and the Vietnamese Mekong Delta from MODIS time-series imagery. Remote Sens. Environ. 2007, 109, 295-313.

15. Leinenkugel, P.; Kuenzer, C.; Dech, S. Comparison and optimisation of MODIS cloud mask products for South East Asia. Int. J. Remote Sens. 2012, 34, 2730-2748.

16. Nguyen, L.; Bui, T. Flood Monitoring of Mekong River Delta, Vietnam using ERS SAR Data. In Proceedings of the 22nd Asian Conference on Remote Sensing, Singapore, 5-9 November 2001. Available online: http:/ / www.crisp.nus.edu.sg/ acrs2001/pdf/147nguye.pdf (accessed on 22 May 2017).

17. Kuenzer, C.; Guo, H.; Huth, J.; Leinenkugel, P.; Li, X.; Dech, S. Flood Mapping and Flood Dynamics of the Mekong Delta: ENVISAT-ASAR-WSM Based Time Series Analyses. Remote Sens. 2013, 5, 687-715.

18. Amitrano, D.; Martino, G.D.; Iodice, A.; Mitidieri, F.; Papa, M.N.; Riccio, D.; Ruello, G. Sentinel-1 for Monitoring Reservoirs: A Performance Analysis. Remote Sens. 2014, 6, 10676-10693.

19. Santoro, M.; Wegmuller, U.; Wiesmann, A.; Lamarche, C.; Bontemps, S.; Defourny, P.; Arino, O. Assessing Envisat ASAR and Sentinel-1 multi-temporal observations to map open water bodies. In Proceedings of the 2015 IEEE 5th Asia-Pacific Conference on Synthetic Aperture Radar (APSAR), Marina Bay Sands, Singapore, 1-4 September 2015; pp. 614-619.

20. ESA. Sentinel-1 Technical Guides. Available online: https://sentinel.esa.int/web/sentinel/technical-guides / sentinel-1-sar (accessed on 22 May 2017).

21. Sentinel Scientific Data Hub. Available online: https:/ / scihub.copernicus.eu/ (accessed on 22 May 2017).

22. SAR Basics with the Sentinel-1 Toolbox in SNAP Tutorial. Available online: http://step.esa.int/main/doc/ tutorials / (accessed on 22 May 2017).

23. Liu, C. Analysis of Sentinel-1 SAR Data for Mapping Standing Water in the Twente Region. Master Thesis on Science in Geo-information Science and Earth Observation, University of Twente, Twente, The Netherlands, February 2016. Available online: http://www.itc.nl/library/papers_2016/msc/wrem/cliu.pdf (accessed on 22 May 2017).

24. Rouse, J.W., Jr.; Haas, R.H.; Schell, J.A.; Deering, D.W. Monitoring Vegetation Systems in the Great Plains with Erts. NASA Spec. Publ. 1974, 351, 309.

25. Rokni, K.; Ahmad, A.; Selamat, A.; Hazini, S. Water Feature Extraction and Change Detection Using Multitemporal Landsat Imagery. Remote Sens. 2014, 6, 4173-4189.

26. Hess, L.L.; Melack, J.M.; Simonett, D.S. Radar detection of flooding beneath the forest canopy: A review. Int. J. Remote Sens. 1990, 11, 1313-1325.

27. Kasischke, E.S.; Bourgeau-Chavez, L.L. Monitoring South Florida Wetlands Using ERS-1 SAR Imagery. Photogramm. Eng. Remote Sens. 1997, 63, 281-291.

28. Pope, K.O.; Rejmankova, E.; Paris, J.F.; Woodruff, R. Detecting seasonal flooding cycles in marshes of the Yucatan Peninsula with SIR-C polarimetric radar imagery. Remote Sens. Environ. 1997, 59, 157-166.

29. Liu, Y.; Chen, K.S.; Xu, P.; Li, Z.L. Modeling and Characteristics of Microwave Backscattering From Rice Canopy Over Growth Stages. IEEE Trans. Geosci. Remote Sens. 2016, 54, 6757-6770.

30. Gstaiger, V.; Huth, J.; Gebhardt, S.; Wehrmann, T.; Kuenzer, C. Multi-sensoral and automated derivation of inundated areas using TerraSAR-X and ENVISAT ASAR data. Int. J. Remote Sens. 2012, 33, 7291-7304.

31. Prigent, C.; Aires, F.; Jimenez, C.; Papa, F.; Roger, J. Multiangle Backscattering Observations of Continental Surfaces in Ku-Band (13 GHz) From Satellites: Understanding the Signals, Particularly in Arid Regions. IEEE Trans. Geosci. Remote Sens. 2015, 53, 1364-1373.

32. Henry, J.B.; Chastanet, P.; Fellah, K.; Desnos, Y.L. Envisat multi-polarized ASAR data for flood mapping. Int. J. Remote Sens. 2006, 27, 1921-1929. 
33. Lehner, B.; Verdin, K.; Jarvis, A. HydroSHEDS Technical Documentation, Version 1.0; World Wildlife Fund US: Washington, DC, USA. Available online: https://hydrosheds.cr.usgs.gov/webappcontent/HydroSHEDS_ TechDoc_v10.pdf (accessed on 22 May 2017).

34. Aires, F.; Miolane, L.; Prigent, C.; Pham-Duc, B.; Fluet-Chouinard, E.; Lerner, B.; Papa, F. A Global Dynamic Long-Term Inundation Extent Dataset at High Spatial Resolution Derived through Downscaling of Satellite Observations. J. Hydrometeorol. 2017, doi:10.1175/JHM-D-16-0155.1.

(C) 2017 by the authors. Licensee MDPI, Basel, Switzerland. This article is an open access article distributed under the terms and conditions of the Creative Commons Attribution (CC BY) license (http://creativecommons.org/licenses/by/4.0/). 